\title{
Intravascular histiocytosis presenting with extensive vulvar necrosis
}

Intravascular histiocytosis (IVH) is a rare reactive cutaneous lesion of unknown pathogenesis. Most cases are reported in association with rheumatoid arthritis, and cutaneous eruptions typically occur near swollen joints. The skin changes have included erythematous and violaceous macules, papules, plaques and indurated patches with a livedo-like pattern of erythema. We report the first case of IVH presenting with florid vulvar necrosis in an 87-year-old patient without a history of rheumatoid arthritis. Physical examination revealed an edematous, exudative and diffusely necrotic vulva with erythema surrounding the areas of necrosis, extending out to the thighs. The debrided skin revealed an extensively necrotic epidermis and multiple clusters of markedly dilated blood vessels within the dermis. These vessels contained fibrin thrombi admixed with numerous $\mathrm{CD}^{+} 8^{+}$and $\mathrm{CD} 63^{+}$histiocytes. Her skin changes improved significantly after surgical debridement and treatment with antibiotics. Interestingly, our patient was also found to have a lupus anticoagulant with elevated anticardiolipin antibodies. This is the first report of IVH possibly related to a thrombogenic diathesis associated with a hypercoagulable state. A diagnosis of IVH is important and may necessitate further clinical evaluation to exclude the possibility of co-existent systemic disease.

Pouryazdanparast P, Yu L, Dalton VK, Haefner HK, Brincat C, Mandell SH, Cho KR, Fullen DR. Intravascular histiocytosis presenting with extensive vulvar necrosis.

\section{Pedram Pouryazdanparast ${ }^{1}$, Limin Yu' ${ }^{1}$, Vanessa K. Dalton², Hope K. Haefner ${ }^{2}$, Cynthia Brincat $^{2}$, Steven H. MandelI, Kathleen R. Cho ${ }^{1,3}$ and Douglas R. Fullen ${ }^{1,4}$}

${ }^{1}$ Department of Pathology, ${ }^{2}$ Department of Obstetrics and Gynecology,

${ }^{3}$ Department of Internal Medicine and

${ }^{4}$ Department of Dermatology, University of Michigan, Ann Arbor, MI, USA

Douglas R. Fullen, MD,

M3261, Medical Science I,

Department of Pathology,

University of Michigan Medical Center,

1301 Catherine, Ann Arbor,

MI 48109-0602, USA

Tel: +17347644460

Fax: +17347644690

e-mail: dfullen@med.umich.edu

Accepted for publication September 24, 2008

J Gutan Pathol 2009; 36 (Suppl. 1): 1-7. (C) 2009 John Wiley \& Sons A/S.

Intravascular histiocytosis (IVH) is a rare benign cutaneous lesion of unknown pathogenesis, characterized by a reactive intravascular dermal proliferation of histiocytes. The majority of reported cases have occurred in association with rheumatoid arthritis; ${ }^{1-4}$ however, cases have been described without associated systemic disease. ${ }^{5}$ The occurrence of IVH has also been reported in a patient with tonsillitis and a patient with an orthopedic metal joint implant. ${ }^{6,7}$ The skin changes seen in IVH accompanying rheumatoid arthritis typically occur near swollen joints. Cutaneous eruptions have included erythematous and violaceous macules, papules, plaques and indurated patches with a livedo-like pattern of erythema. ${ }^{1-4,8}$

We report the first case of IVH in a patient without a history of rheumatoid arthritis, presenting with florid vulvar necrosis and found to have a lupus anticoagulant with elevated anticardiolipin antibodies. The overlap in clinical and histologic features that may occur with IVH and reactive angioendotheliomatosis (RAE) are reviewed. The important differential diagnoses considered in this case, the possible histogenesis of this lesion and the importance of considering further clinical evaluation of patients who present with IVH are discussed.

\section{Case report}

An 87-year-old woman with a medical history of hypertension, myocardial infarction and Alzheimer's dementia had a 1-year history of vulvar pruritus treated with topical antifungal creams. There was no 


\section{Pouryazdanparast et al.}

known history of rheumatoid arthritis. One month prior to her presentation at our institution, she had an insidious onset of vulvar itching and increasing pain despite treatment with topical antifungals. She was referred to a gynecologist at an outside institution, and physical examination revealed superficial labial ulcerations as well as edema and erythema of both labia majora, extending to the proximal inner thighs. It was felt that her vulvar lesion was the result of an acute vulvitis and she was initiated on antiviral and antibiotic therapy. However, viral and bacterial swab cultures were negative.

Over the ensuing 2 weeks, she developed worsening pain, pruritus and areas of acute vulvar necrosis. Skin biopsies of the vulvar lesion were performed and sent for review to the Department of Pathology at the University of Michigan. Microscopically, the vulvar biopsies showed prominent thrombosis of the superficial dermal blood vessels with associated dermal necrosis and vasoproliferative features suggestive of prior stasis dermatitis. No intravascular proliferations were noted, and the vascular thrombosis was present without vasculitis. The histopathologic features suggested a thrombogenic diathesis associated with a hypercoagulable state and a recommendation was made for medical evaluation of an acquired coagulopathy. Her treatment was then expanded to include a course of steroids. Hypercoagulability studies were performed and revealed the presence of a lupus anticoagulant along with an elevation in anticardiolipin immunoglobulin $\operatorname{IgM}$ antibodies $(11 \mathrm{U} / \mathrm{ml})$, suggestive of a possible underlying coagulopathy. Her protein $\mathrm{S}$ and protein $\mathrm{C}$ levels as well as prothrombin and partial thromboplastin times were within the normal range.

She was then referred to the University of Michigan Center for Vulvar Diseases to undergo further evaluation. However, prior to her scheduled appointment, she presented to our emergency department with an acute exacerbation of severe vulvar pain and pruritus. Physical examination revealed an edematous, exudative, and diffusely necrotic vulva with erythema surrounding the areas of necrosis, extending out to the thighs (Fig. 1). In light of the worsening necrosis and failure of medical treatment, she was taken to the operating room and underwent radical debridement of her diffusely necrotic vulva.

Her surgery was complicated by an intra-operative myocardial infarction, and transthoracic echocardiography revealed a small and chronic thrombus within the left ventricle. Also, cultures of vulvar tissue performed during the operation revealed growth of coagulase-negative Staphylococcus, alpha-hemolytic Streptococcus, multiple strains of Bacteroides fragilis group and non-perfringens Clostridium species.

Histopathologic examination of the debrided skin revealed an extensively necrotic and ulcerated

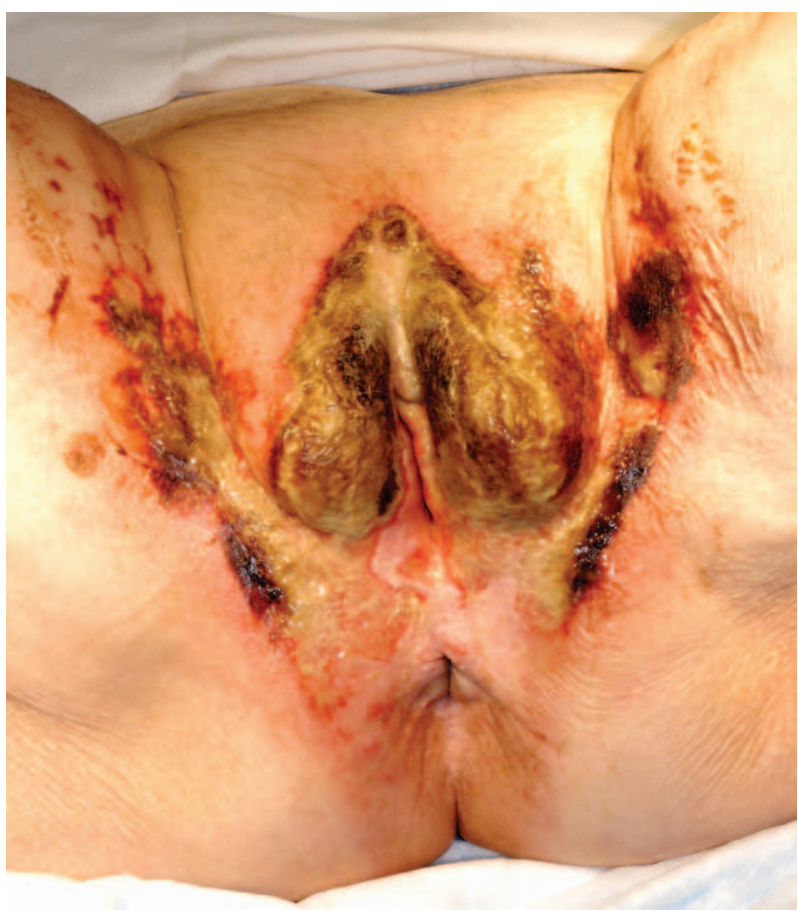

Fig. 1. Pre-operatively, an edematous, exudative and diffusely necrotic vulva with erythema surrounding the areas of necrosis, extending out to the thighs.

epidermis with associated neutrophilic abscess. Within the majority of the papillary and reticular dermis, there were multiple clusters of markedly dilated blood vessels (Fig. 2). The lumens of these dilated blood vessels were composed of numerous pale-staining histiocytoid mononuclear cells, a few bland-appearing endothelial cells and sparse benignappearing lymphocytes (Fig. 3A,B). Many of these vessels also contained fibrin thrombi, demonstrated by periodic acid-Schiff stain (Fig. 4). The

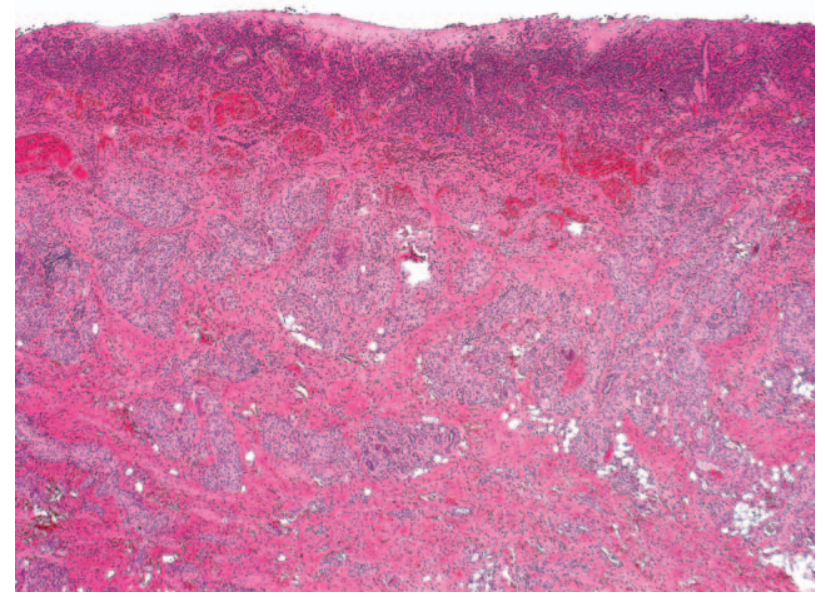

Fig. 2. The vulvar skin is extensively necrotic with ulcerated epidermis and associated neutrophilic abscess. Within the dermis, there are multiple clusters of markedly dilated blood vessels (hematoxylin and eosin stain, original magnification $\times 25$ ). 

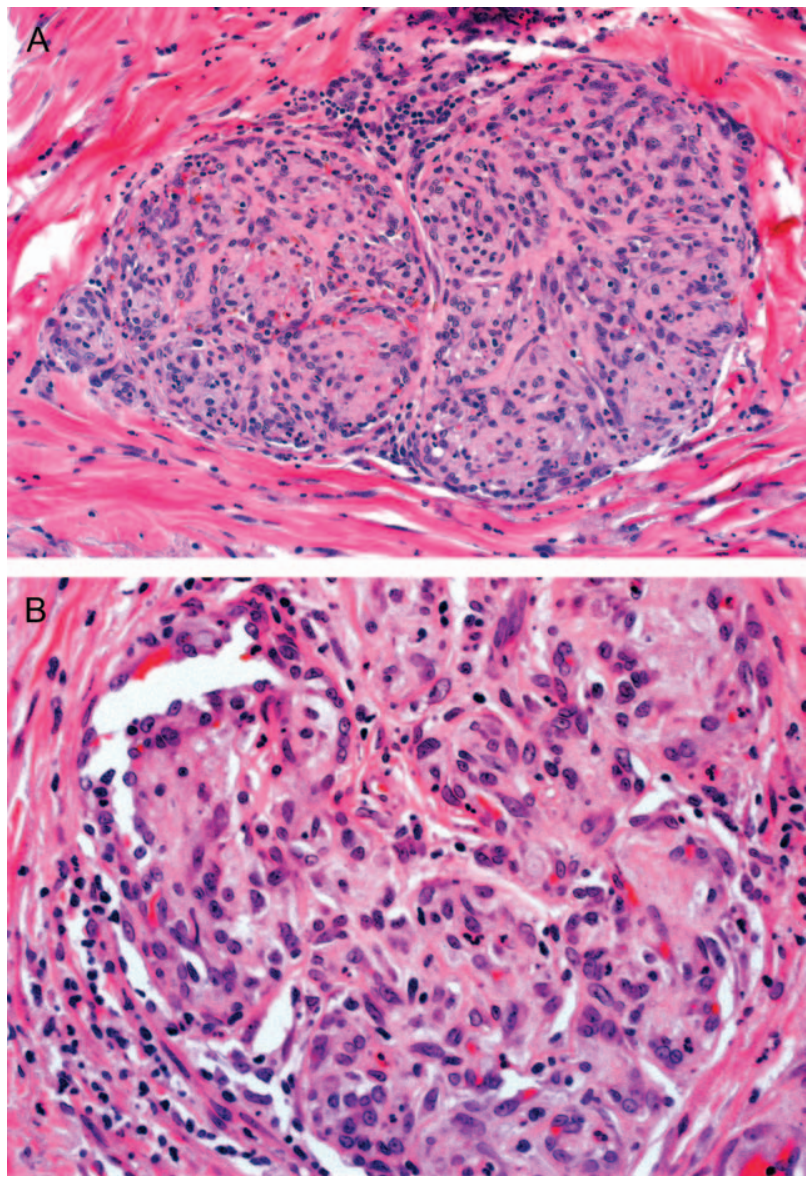

Fig. 3. Medium (A) and high (B) power views showing the dilated blood vessels composed predominantly of numerous pale-staining histiocytoid mononuclear cells, a few bland-appearing endothelial cells and sparse benign-appearing lymphocytes (hematoxylin and eosin stain, original magnification: $\mathrm{A}, \times 200$ and $\mathrm{B}, \times 400)$.

mononuclear cells appeared to be histiocytes with abundant pale granular cytoplasm and large, roundto-oval, nuclei without atypia. The endothelial cells appeared bland, lacking pleomorphism, nuclear

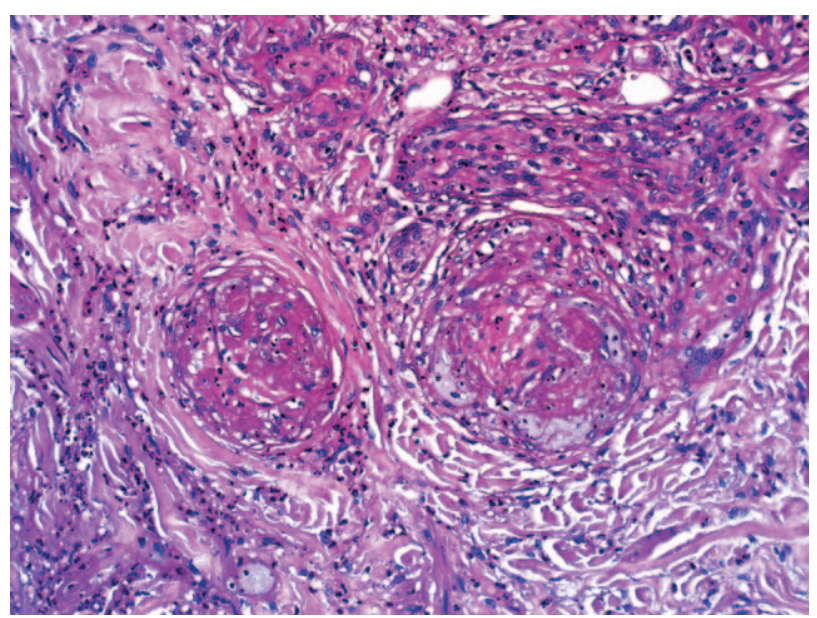

Fig. 4. Vessel lumens contain fibrin thrombi, which is shown by periodic acid-Schiff stain (original magnification $\times 200$ ).
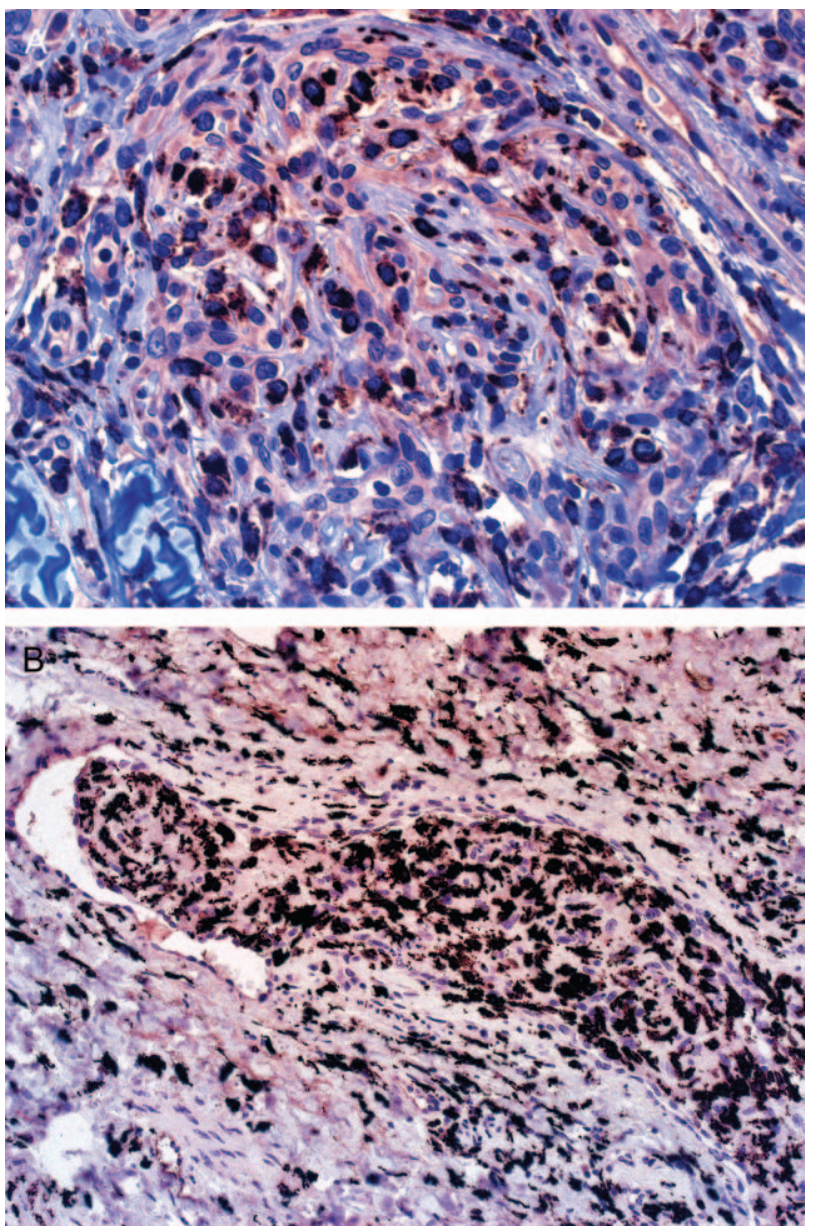

Fig. 5. Immunohistochemistry showing the numerous intraluminal histiocytes expressing (A) CD68 and (B) CD163. Interstitial dermal dendritic cells also show CD163 positivity (original magnification: $\mathrm{A}, \times 400$ and $\mathrm{B}, \times 200)$.

hyperchromasia, and prominent nucleoli. Rare endothelial mitoses were seen; however, no atypical mitotic figures were identified. Extravasated erythrocytes and a mild inflammatory infiltrate of benignappearing lymphocytes were noted within the dermis and around the dilated vascular clusters. No fungal organisms were identified with Grocott Methenamine Silver stain.

Immunohistochemical examination revealed the predominant mononuclear intraluminal cells to be $\mathrm{CD}^{+} 8^{+}$and $\mathrm{CD} 163^{+}$histiocytes (Fig. 5A,B). Interstitial dermal dendritic cells were also highlighted by CD163. The few intravascular endothelial cells and those lining the dilated blood vessels were strongly positive for CD31 and CD34, with a linear and evenly distributed membranous staining pattern (Fig. 6). Occasional intraluminal histiocytes were also highlighted by CD31 and showed a more granular and weak intensity of membranous staining compared to the endothelial cells. Immunohistochemistry performed with smooth muscle-specific actin identified 


\section{Pouryazdanparast et al.}

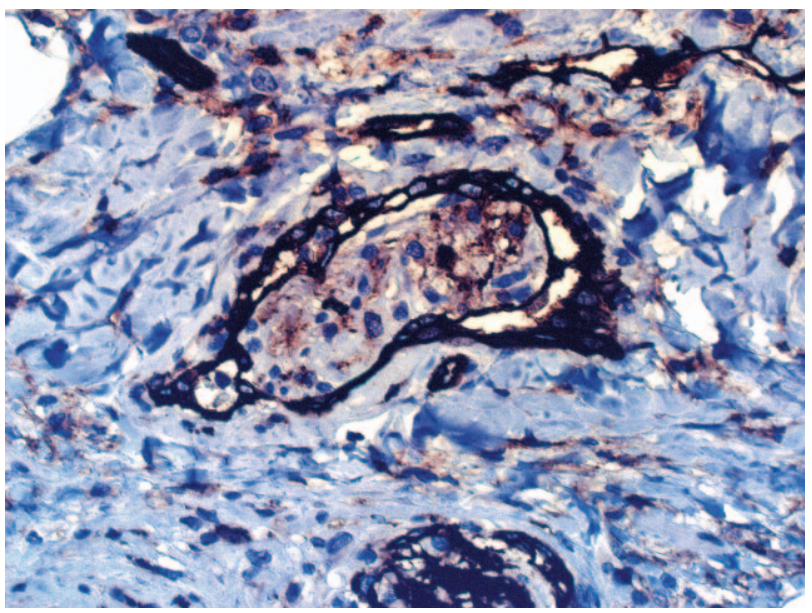

Fig. 6. Immunohistochemistry showing strong CD31 expression of endothelial cells lining the dilated blood vessels. The few endothelial cells within the intravascular spaces also show CD31 reactivity (original magnification $\times 400$ ).

a proliferation of bland appearing pericytes surrounding the dilated blood vessels. Antibodies to kappa and lambda light chains stained rare polytypic plasma cells in the dermis but did not stain the cells within the dilated vessels. Occasional CD ${ }^{+}{ }^{-}$-cells and CD20 ${ }^{+}$ $\mathrm{B}$-cells were also present within the vascular aggregates and in the dermal inflammatory infiltrate. In addition, leukocyte common antigen (CD45) staining was primarily restricted to a few intraluminal lymphocytes and histiocytes as well as dermal inflammatory lymphocytes. Furthermore, the endothelial cells lining the dermal lymphatics were strongly positive for D2-40, a selective marker for lymphatic endothelium. These lymphatics did not contain the intraluminal proliferations (Fig. 7) and the endothelium surrounding the vascular proliferations was negative for the expression of D2-40. This confirmed

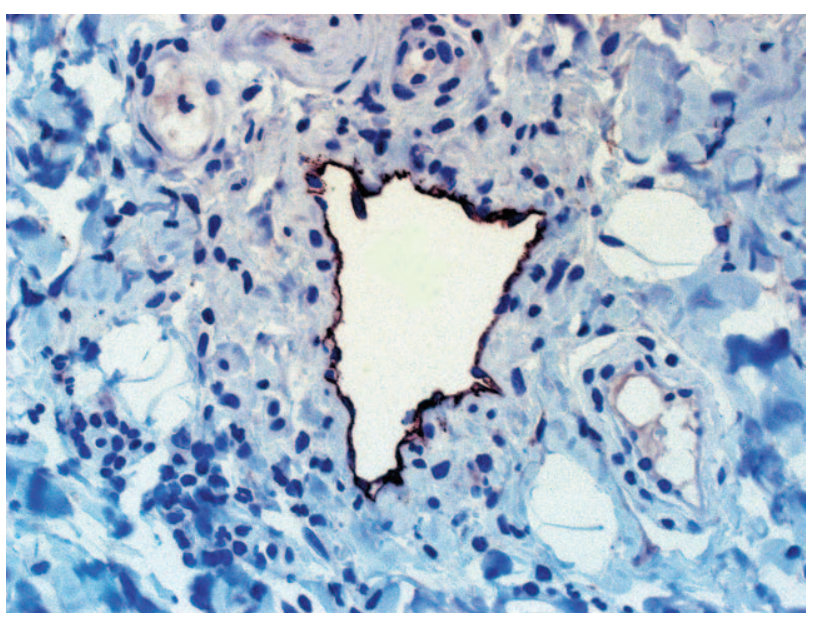

Fig. 7. Immunohistochemistry showing strong D2-40 expression of endothelial cells lining the dermal lymphatics. These lymphatics do not contain the intraluminal proliferations (original magnification $\times 400)$. that the reactive proliferation was within dermal blood vessels and not lymphatics. Also, the proliferating intravascular cells showed no immunoreactivity with S-100 protein or cytokeratins.

This case was independently reviewed by several staff pathologists and two dermatopathologists in our department. The consensus opinion was that this lesion represented a benign reactive process, probably within the spectrum of RAE. However, given the unusual clinical presentation and histopathologic findings, the case was sent for additional review to an outside consultant. The consultant agreed with our interpretation and also interpreted the lesion as "reactive". Given the very striking histiocytic proliferation within the dermal blood vessels, we favored a diagnosis of IVH.

Five days after debridement, the vulvar lesion appeared to be healing well with minimal erythema and no necrosis (Fig. 8). She was discharged with antibiotics, continuation of her previous aspirin therapy, and home nursing for wound care. Ten weeks after discharge, the lesional areas were almost completely healed.

\section{Discussion}

This case represents an unusual and exuberant presentation of the rare cutaneous lesion known as IVH. To our knowledge, this is the first reported case of IVH presenting with florid vulvar necrosis. Interestingly, a case of IVH has been documented in a patient with tonsillitis who presented with edema, erythema, and necrosis of the scrotum. ${ }^{6}$ However, the clinical changes in our case were more extensive and our patient was found to have a lupus anticoagulant with elevated anticardiolipin IgM antibodies. The finding of a hypercoagulable state in a patient with cutaneous lesions of IVH has not been previously reported. Also, in contrast to most reported cases of

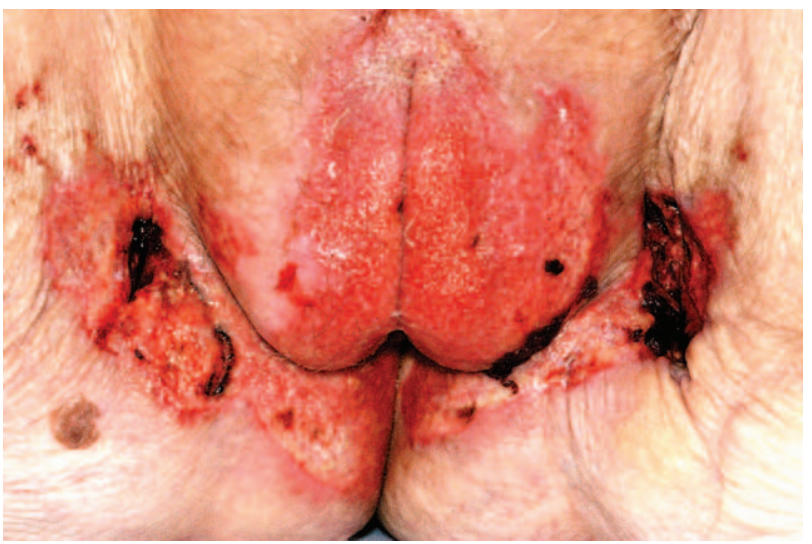

Fig. 8. Five days post-debridement. Healing vulvar lesions with minimal erythema and no necrosis. 
IVH with vulvar necrosis

IVH, our patient had no clinical history or symptoms to suggest an associated rheumatoid arthritis.

The clinical and histopathologic appearance of this case posed a diagnostic challenge because of several overlapping features of IVH that can also be observed with RAE. Perhaps not unexpectedly, the literature has at times been confusing in this regard, and the terms IVH and RAE have been used interchangeably in some settings. ${ }^{4,9}$ Clinically, the cutaneous lesions in both IVH and RAE can present as erythematous to violaceous macules, patches, papules, and nodules that may undergo ulceration and necrosis. ${ }^{1-4,10}$ Furthermore, most cases of IVH have been reported in association with rheumatoid arthritis whereas RAE can co-exist with many other systemic diseases including antiphospholipid syndrome, subacute bacterial endocarditis, cryoglobulinemia, renal disease, peripheral vascular disease, lupus erythematous, and arteriovenous shunt. ${ }^{11}$ The association of RAE with rheumatoid arthritis has been documented in one case. ${ }^{12}$

The histopathologic appearance of this case initially resembled RAE because of the proliferation of multiple prominent clusters of closely packed dermal blood vessels. These vessels were lined by bland appearing endothelial cells, many of which contained fibrin thrombi. The reactive dermal alterations typically seen with RAE were also observed and included extravasated erythrocytes and an inflammatory infiltrate composed of benignappearing lymphocytes. Although a proliferation of endothelial cells within vascular spaces can be observed with RAE, not all reported cases have showed this finding. A recent review of the clinicopathologic features of 15 RAE cases stressed the variety of histologic manifestations, including a predominately extravascular morphology. ${ }^{11}$ Examination of our case revealed that the intravascular proliferations were composed of numerous histiocytoidappearing mononuclear cells. Immunohistochemical studies confirmed these cells to be $\mathrm{CD}^{\circ}{ }^{+}$and $\mathrm{CD} 163^{+}$histiocytes confined to dermal blood vessels. Occasional intravascular histiocytes also expressed CD31. The finding of CD31 ${ }^{+}$histiocytes has been shown to be a potential pitfall in misdiagnosing such lesions as a purely vascular proliferation. ${ }^{13}$ In our case, the CD31 reactivity in histiocytes showed a granular and less intense membranous expression pattern compared with the more linear and intense staining pattern observed in the endothelial cells lining the dilated blood vessels. Also, an unusual finding in this case was the presence of extensive epidermal necrosis and intravascular fibrin thrombi. These morphologic changes have been reported, albeit to a lesser degree, in one other case of IVH. ${ }^{6}$ In view of the striking histiocytic proliferation, a finding not usually seen in lesions that have been reported as
RAE, we felt that this lesion best represented a diagnosis of IVH rather than RAE.

Given the unusual and florid clinical presentation of this case as well as the extensive intravascular dermal proliferation, other benign and malignant cutaneous vascular lesions were considered in the differential diagnosis. These entities included intravascular lymphoma, epithelioid angiosarcoma, glomeruloid hemangioma, acroangiodermatitis and Melkersson-Rosenthal disease (Table 1).

In addition, because of the clustered and epithelioid nature of the IVH, a melanoma or metastatic carcinoma were also considered in the differential diagnosis. Immunohistochemical staining for S-100 protein and cytokeratins failed to show reactivity of the intravascular cells. As such, we were confident that this lesion did not represent a melanoma or a metastatic carcinoma.

Given that IVH is a rare cutaneous lesion, the true pathogenesis remains to be elucidated. Rieger et al. ${ }^{4}$ contend that IVH is not an entity on its own but may represent a stage of RAE. They suggest that the histiocytes are the residual cells associated with the organization of microthrombi, which is later followed by endothelial cell proliferation. Due to the frequent association with certain systemic diseases, others have speculated that IVH and RAE are two different manifestations or stages of the same disease and may represent a spectrum of cutaneous reactive angiomatoses. ${ }^{14}$ Also, given the reported association with rheumatoid arthritis, IVH may arise in the setting of systemic inflammatory conditions. In the context of rheumatoid arthritis, it has been proposed that the pathogenesis may involve the drainage of histiocytes from the lymphatics of inflamed joints. ${ }^{3}$ However, IVH occurring without the co-existence of rheumatoid arthritis is very rare, making it difficult to define the etiologic factors involved with pathogenesis. Our patient did not have a history of rheumatoid arthritis. However, she did have a multibacterial vulvar infection and histopathologic findings of numerous intravascular thrombi, in the setting of a hypercoagulable state. Therefore, it may be possible that a vascular reaction to bacterial antigens and/or intravascular thrombi occurred, resulting in this unusual and florid presentation of IVH. Nonetheless, further investigation of additional cases will be necessary to unravel the pathogenesis of IVH.

In summary, IVH may share some overlapping clinical and histologic features with other benign vascular lesions such as RAE. Morphologically, the predominance of an intravascular histiocytic component can aid in distinguishing between these two entities. Our case is the first documented report of IVH occurring in a patient without a history of rheumatoid arthritis who presented with extensive 


\section{Pouryazdanparast et al.}

Table 1. Differential diagnostic considerations with clinico-histopathologic comparisons to this case of intravascular histiocytosis

\begin{tabular}{|c|c|c|c|}
\hline Entity & Clinical features & Histopathologic features & $\begin{array}{l}\text { Clinico-histopathologic features } \\
\text { of this case }\end{array}$ \\
\hline Intravascular lymphoma & $\begin{array}{l}\text { Erythematous or violaceous nodules, } \\
\text { patches, and plaques. Multisystem } \\
\text { organ involvement with an } \\
\text { aggressive and rapidly fatal course. }\end{array}$ & $\begin{array}{l}\text { A proliferation of large atypical } \\
\text { B-lymphocytes filling dilated blood } \\
\text { vessels within the dermis. }\end{array}$ & $\begin{array}{l}\text { No evidence of multisystem organ } \\
\text { involvement. The vessels were } \\
\text { composed of histiocytes and only } \\
\text { a few benign lymphocytes. }\end{array}$ \\
\hline $\begin{array}{l}\text { Epithelioid } \\
\quad \text { angiosarcoma }\end{array}$ & $\begin{array}{l}\text { Red-to-violaceous patches, plaques, } \\
\text { and nodules occurring on the lower } \\
\text { extremities. Risk factors include } \\
\text { radiation exposure }{ }^{15} \text { or foreign } \\
\text { body reactions. }\end{array}$ & $\begin{array}{l}\text { Islands or sheets of pleomorphic } \\
\text { epithelioid endothelial cells in } \\
\text { a desmoplastic stroma, without } \\
\text { intravascular involvement. Tumor } \\
\text { cells may co-express CD31, CD34 } \\
\text { and cytokeratins. }\end{array}$ & $\begin{array}{l}\text { No history of radiation exposures or } \\
\text { foreign body reactions. The } \\
\text { endothelial cells were benign in } \\
\text { appearance, lined the vascular } \\
\text { structures, and lacked } \\
\text { immunohistochemical expression } \\
\text { for cytokeratins. }\end{array}$ \\
\hline $\begin{array}{l}\text { Glomeruloid } \\
\text { hemangioma }\end{array}$ & $\begin{array}{l}\text { Erythematous or violaceous papules } \\
\text { on the trunk and proximal } \\
\text { extremities. Usually occurs in the } \\
\text { setting of POEMS (Polyneuropathy, } \\
\text { Organomegaly, Endocrinopathy, } \\
\text { Monoclonal gammopathy, and Skin } \\
\text { changes) syndrome. }\end{array}$ & $\begin{array}{l}\text { Dilated vascular spaces containing } \\
\text { aggregates of small capillaries } \\
\text { lined by plump endothelial cells, } \\
\text { resembling renal glomeruli. The } \\
\text { endothelial cells may contain } \\
\text { PAS-positive eosinophilic globules. } \\
\text { Fibrin thrombi are not observed. }\end{array}$ & $\begin{array}{l}\text { No evidence of POEMS syndrome. } \\
\text { Dilated clusters of dermal blood } \\
\text { vessels composed of histiocytes, } \\
\text { some containing fibrin thrombi. No } \\
\text { PAS-positive eosinophilic globules } \\
\text { were noted within endothelial cells. }\end{array}$ \\
\hline Acroangiodermatitis & $\begin{array}{l}\text { Violaceous papules and plaques on } \\
\text { the lower extremities. Occurs in the } \\
\text { setting of chronic venous } \\
\text { insufficiency, arteriovenous } \\
\text { malformation, or a surgically } \\
\text { constructed arteriovenous } \\
\text { fistula. }{ }^{19,20}\end{array}$ & $\begin{array}{l}\text { A lobular dermal proliferation of thick- } \\
\text { walled blood vessels with } \\
\text { prominent endothelial cells. There } \\
\text { is background dermal edema, } \\
\text { fibrosis, extravasation of red blood } \\
\text { cells, and hemosiderin pigment } \\
\text { deposition. }\end{array}$ & $\begin{array}{l}\text { No history of chronic venous } \\
\text { insufficiency, arteriovenous } \\
\text { malformations or arteriovenous } \\
\text { fistula. An intravascular } \\
\text { proliferation composed of } \\
\text { histiocytes rather than endothelial } \\
\text { cells. No hemosiderin deposition, } \\
\text { dermal edema or fibrosis was } \\
\text { noted. }\end{array}$ \\
\hline $\begin{array}{l}\text { Melkersson-Rosenthal } \\
\text { disease }\end{array}$ & $\begin{array}{l}\text { A triad of recurrent orofacial edema, } \\
\text { facial paralysis, and fissured } \\
\text { tongue. Vulvar edema may occur. } \\
\text { There may be an association with } \\
\text { Crohn's disease. }\end{array}$ & $\begin{array}{l}\text { The dermis contains non-caseating } \\
\text { granulomas (usually extravascular), } \\
\text { often with multinucleated } \\
\text { giant-cells, and a perivascular } \\
\text { lymphocytic inflammatory infiltrate. }\end{array}$ & $\begin{array}{l}\text { No known history of Crohn's disease. } \\
\text { A vulvar lesion with an } \\
\text { intravascular proliferation of } \\
\text { histiocytes. No extravascular } \\
\text { granulomas were observed. }\end{array}$ \\
\hline
\end{tabular}

PAS, periodic acid-Schiff.

vulvar necrosis. The clinical presentation of IVH was not distinctive in this case and indicates that cutaneous manifestations of IVH may be more variable than previously reported. Recurrences of IVH have been reported, ${ }^{3,5,7}$ and currently, there is no specific therapy. Treatment is usually directed toward associated systemic illnesses. Interestingly, our patient was found to have a lupus anticoagulant with elevated anticardiolipin antibodies, representing the first report of IVH possibly related to a thrombogenic diathesis associated with a hypercoagulable state. Thus, a diagnosis of IVH is important and may necessitate further clinical evaluation to exclude the possibility of co-existent systemic disease.

\section{Acknowledgement}

We would like to express our sincere appreciation to Dr Christopher Fletcher for his consultation on this case.

\section{References}

1. Okazaki A, Asada H, Niizeki H, Nonomura A, Miyagawa S. Intravascular histiocytosis associated with rheumatoid arthritis: report of a case with lymphatic endothelial proliferation. Br J Dermatol 2005; 152: 1385.
2. Takiwaki H, Adachi A, Kohno H, Ogawa Y. Intravascular or intralymphatic histiocytosis associated with rheumatoid arthritis: a report of 4 cases. J Am Acad Dermatol 2004; 50: 585.

3. Pruim B, Strutton G, Congdon S, Whitehead K, Donaldson E. Cutaneous histiocytic lymphangitis: an unusual manifestation of rheumatoid arthritis. Australas J Dermatol 2000; 41: 101.

4. Rieger E, Soyer HP, Leboit PE, Metze D, Slovak R, Kerl H. Reactive angioendotheliomatosis or intravascular histiocytosis? An immunohistochemical and ultrastructural study in two cases of intravascular histiocytic cell proliferation. Br J Dermatol 1999; 140: 497.

5. O'Grady JT, Shahidullah H, Doherty VR, al-Nafussi A. Intravascular histiocytosis. Histopathology 1994; 24: 265.

6. Asagoe K, Torigoe R, Ofuji R, Iwatsuki K. Reactive intravascular histiocytosis associated with tonsillitis. Br J Dermatol 2006; 154: 560.

7. Watanabe T, Yamada N, Yoshida Y, Yamamoto O. Intralymphatic histiocytosis with granuloma formation associated with orthopaedic metal implants. Br J Dermatol 2008; 158: 402.

8. Catalina-Fernandez I, Alvarez AC, Martin FC, Fernandez-Mera JJ, Saenz-Santamaria J. Cutaneous intralymphatic histiocytosis associated with rheumatoid arthritis: report of a case and review of the literature. Am J Dermatopathol 2007; 29: 165.

9. Mensing CH, Krengel S, Tronnier M, Wolff HH. Reactive angioendotheliomatosis: is it 'intravascular histiocytosis'? J Eur Acad Dermatol Venereol 2005; 19: 216.

10. Kirke S, Angus B, Kesteven PJ, Calonje E, Simpson N. Localized reactive angioendotheliomatosis. Clin Exp Dermatol 2007; 32: 45. 
11. McMenamin ME, Fletcher CD. Reactive angioendotheliomatosis: a study of 15 cases demonstrating a wide clinicopathologic spectrum. Am J Surg Pathol 2002; 26: 685.

12. Tomasini C, Soro E, Pippione M. Angioendotheliomatosis in a woman with rheumatoid arthritis. Am J Dermatopathol 2000; 22: 334.

13. McKenney JK, Weiss SW, Folpe AL. CD31 expression in intratumoral macrophages: a potential diagnostic pitfall. Am J Surg Pathol 2001; 25: 1167.

14. Rongioletti F, Rebora A. Cutaneous reactive angiomatoses: patterns and classification of reactive vascular proliferation. J Am Acad Dermatol 2003; 49: 887.

15. Fletcher CD, Beham A, Bekir S, Clarke AM, Marley NJ. Epithelioid angiosarcoma of deep soft tissue: a distinctive tumor readily mistaken for an epithelial neoplasm. Am J Surg Pathol 1991; 15: 915.

16. Jennings TA, Peterson L, Axiotis CA, Friedlaender GE, Cooke RA, Rosai J. Angiosarcoma associated with foreign body material. A report of three cases. Cancer 1988; 62: 2436.

17. Prescott RJ, Banerjee SS, Eyden BP, Haboubi NY. Gutaneous epithelioid angiosarcoma: a clinicopathological study of four cases. Histopathology 1994; 25: 421.
18. McCluggage WG, Clarke R, Toner PG. Cutaneous epithelioid angiosarcoma exhibiting cytokeratin positivity. Histopathology 1995; 27: 291.

19. Kim TH, Kim KH, Kang JS, Kim JH, Hwang IY. PseudoKaposi's sarcoma associated with acquired arteriovenous fistula. J Dermatol 1997; 24: 28.

20. Larralde M, Gonzalez V, Marietti R, Nussembaum D, Peirano M, Schroh R. Pseudo-Kaposi sarcoma with arteriovenous malformation. Pediatr Dermatol 2001; 18: 325.

21. Tsuboi H, Masuzawa M, Katsuoka K. A case of vulvitis granulomatosa. J Dermatol 2005; 32: 831.

22. Ratzinger G, Sepp N, Vogetseder W, Tilg H. Cheilitis granulomatosa and Melkersson-Rosenthal syndrome: evaluation of gastrointestinal involvement and therapeutic regimens in a series of 14 patients. J Eur Acad Dermatol Venereol 2007; 21: 1065 .

\section{Note added after online publication: conflicts of interest}

None declared. 